\title{
Affibody-Modified Gd@C-Dots with Efficient Renal Clearance for Enhanced MRI of EGFR Expression in Non-Small-Cell Lung Cancer
}

This article was published in the following Dove Press journal: International Journal of Nanomedicine

\author{
Yongyi $\mathrm{Wu}^{1,2, *}$ \\ Haoxiang $\mathrm{Li}^{1,2, *}$ \\ Yuling Yan ${ }^{1,2, *}$ \\ Kai Wang ${ }^{1,2}$ \\ Yongna Cheng ${ }^{1,2}$ \\ Yangyang $\mathrm{Li}^{1,2}$ \\ Xinyuan $\mathrm{Zhu}^{3}$ \\ Jin Xie $\mathbb{D}^{4}$ \\ Xilin Sun $\mathbb{1 D}^{1,2}$
}

'NHC and CAMS Key Laboratory of Molecular Probe and Targeted

Theranostics, Molecular Imaging Research Center (MIRC), Harbin Medical University, Harbin, Heilongjiang, I 50028, People's Republic of China; ${ }^{2}$ TOF-PET/CT/MR Center, The Fourth Hospital of Harbin Medical University, Harbin, Heilongjiang I 50028, People's Republic of China; ${ }^{3}$ School of Chemistry and Chemical Engineering, Shanghai Key Laboratory for Molecular Engineering of Chiral Drugs, Shanghai Jiao Tong University, Shanghai 200240, People's Republic of China; ${ }^{4}$ Department of Chemistry and Bio-Imaging Research Center, The University of Georgia, Athens, Georgia 30602, USA

*These authors contributed equally to this work

Correspondence: Xilin Sun

$\mathrm{NHC}$ and CAMS Key Laboratory of

Molecular Probe and Targeted

Theranostics, Molecular Imaging Research

Center, Harbin Medical University, 766

Xiangan N Street, Songbei District,

Harbin, Heilongjiang 150028, People's

Republic of China

Fax +86-45I-82576509

Email sunx|@ems.hrbmu.edu.cn

Jin Xie

Department of Chemistry, University of Georgia, Athens, GA 30602, USA

Email jinxie@uga.edu
Purpose: Gd-encapsulated carbonaceous dots (Gd@C-dots) have excellent stability and magnetic properties without free Gd leakage, therefore they can be considered as a safe alternative $\mathrm{T} 1$ contrast agent to commonly used Gd complexes. To improve their potential for cancer diagnosis and treatment, affibody-modified Gd@C-dots targeting non-small-cell lung cancer (NSCLC) EGFR-positive tumors with enhanced renal clearance were developed and synthesized.

Materials and Methods: Gd@C-dots were developed and modified with Ac-Cys- $Z_{\mathrm{EGFR}: 1907}$ through EDC/NHS. The size, morphology, and optical properties of the Gd@C-dots and

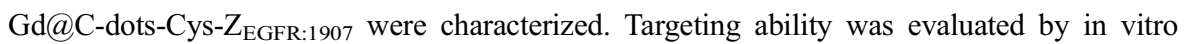
and in vivo experiments, respectively. Residual gadolinium concentration in major organs was detected with confocal imaging and inductively coupled plasma mass spectrometry (ICP-MS) ex vivo. H\&E staining was used to assess the morphology of these organs.

Results: Gd@C-dots with nearly 20 nm in diameter were developed and modified with Ac-

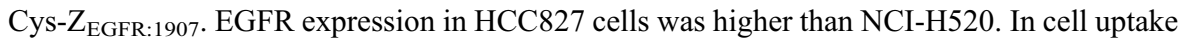
assays, EGFR-expressing HCC827 cells exhibited significant MR T1WI signal enhancement when compared to NCI-H520 cells. Cellular uptake of Gd@C-dots-Cys- $Z_{\text {EGFR:1907 was }}$

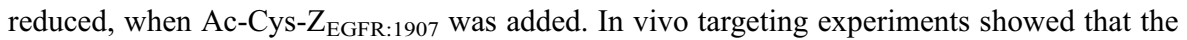
probe signal was significantly higher in HCC827 than NCI-H520 xenografts at $1 \mathrm{~h}$ after injection. In contrast to Gd@C-dots, Gd@C-dots-Cys-Z Z EGFR:1907 nanoparticles can be efficiently excreted through renal clearance. No morphological changes were observed by $H \& E$ staining in the major organs after injection of Gd@C-dots-Cys-Z

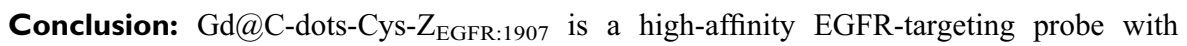
efficient renal clearance and is therefore a promising contrast agent for clinical applications such as diagnosis and treatment of NSCLC EGFR-positive malignant tumors.

Keywords: Gd@C-dots, EGFR, MRI, nanoparticles, efficient renal clearance

\section{Introduction}

Nanomedicine is a promising approach that may provide significant breakthroughs in medicine and healthcare. ${ }^{1}$ Indeed, nanotechnology has allowed to overcome important limitations of traditional magnetic resonance imaging (MRI) contrast agents due to the properties and surface modifications of nanoparticles, ultimately leading to the improvement of diagnosis efficacy. ${ }^{2}$ MRI contrast agents increase the sensitivity of MR scans and thereby improve diagnostic accuracy, particularly in malignant disease. To date, paramagnetic Gd-chelates, such as Gd-DTPA, Gd-DTPA-BMA, Gd-DOTA, 
are more widely used in clinical diagnosis among the MRI contrast agents. However, these chelates are non-specific contrast agents and therefore cannot differentiate molecular expression in tumors, which is necessary to guide targeted therapy. Moreover, gadolinium linear complexes can release free gadolinium ions in the body, which may cause severe nephrogenic systemic fibrosis (NSF) due to their toxicity, particularly in patients with renal diseases or poor renal functions. ${ }^{3,4}$

Recently, nanoparticle-based MRI contrast agents have received increasing attention because of their many advantages. For instance, Gd nanoparticles exhibit reduced toxicity profiles by preventing $\mathrm{Gd}^{3+}$ leakage from traditional chelates. Thus, several Gd nanoparticles have been developed over the past decade, including $\mathrm{Gd}_{2} \mathrm{O} 3,{ }^{5}$ Gd-based silica nanoparticles, ${ }^{6}$ and $\mathrm{Gd}-\mathrm{Si}$ oxide nanoparticles. ${ }^{7}$ However, due to their surface properties and relatively large size, these nanoparticles accumulate heavily in the reticuloendothelial (RES) organs after systemic injection, particularly in the liver and spleen. To overcome this limitation, we recently developed Gd-based nanoparticles with efficient renal clearance. ${ }^{8}$ The Gd@C-dots have shown relatively high $\mathrm{T} 1$ relaxivity with steerable size and low toxicity, and can be eliminated by the renal system quickly without leakage of free Gd(III) to the plasma or urine. And this efficient renal clearance makes Gd@C-dots a safer MRI agent. ${ }^{8}$

Although nanoparticles modify with specific targeting peptides provide accurate cancer diagnosis, imaging the lung with MRI remains challenging. ${ }^{9}$ Most of nuclear magnetic resonance (NMR) signals generated from MRI based on the hydrogen nuclei of water molecules. However, there's a lot of air in the lungs which leads to an inherently low signal-to-noise ratio. Moreover, the high difference between the magnetic susceptibility of the air cavity and the tissue in the lung brings the chemical displacement artifact of the air. Finally, because of the long scanning time, the artifact of respiratory movement becomes a problem to solve. Thus, the use of MRI contrast agents can make up for the deficiencies and improve diagnostic accuracy. There is therefore currently a need to develop effective contrast agents to improve the potential of MRI in detecting malignant lung cancer.

Epidermal growth factor receptor (EGFR) is a wellestablished tumor biomarker, which is overexpressed in a wide range of human tumors, such as breast cancer, brain tumor, and particularly lung cancer, where it is associated with tumor proliferation, metastasis and angiogenesis. ${ }^{10,11}$ Besides,
anti-EGFR therapy is one of the most advanced and effective treatments for EGFR-overexpressing tumors. ${ }^{12,13}$ Thus, distinguishing EGFR expression in tumors is crucial for precision anti-EGFR therapy. Affibodies have shown great promise as tumor-targeting agents. ${ }^{14-16}$ Several anti-EGFR affibodies, including Ac-Cys- $Z_{\mathrm{EGFR}}$ : 1907, exhibit high affinities in the $\mathrm{nM}$ ranges, and have been used for tumor imaging. To date, Ac-Cys-Z $Z_{\text {EGFR: } 1907}$ shows the best in vivo tumor-targeting properties. ${ }^{16-19}$

In this study, we developed Gd@C-dots nanoparticles with surface carboxyl groups modified with AcCys-Z $Z_{\text {EGFR: } 1907}$ by following a synthesis method reported in. ${ }^{20} \mathrm{We}$ assessed the applicability of this nanoprobe in diagnosing EGFR-positive tumors with MRI in non-smallcell lung cancer (NSCLC) (Figure 1).

\section{Materials and Methods \\ Synthesis of Gd@C-Dots-Cys-Z EGFR: 1907} The preparation was optimized to obtain proper sized Gd@C-dots. Briefly, we first synthesized mesoporous silica nanoparticles (MSNs) with an average diameter of $160 \mathrm{~nm}$ and a pore size of $20 \mathrm{~nm}$ (hereafter designated as MSN-20). For the synthesis of MSNs, according to previous reports. ${ }^{20}$ Briefly, dissolve $0.6 \mathrm{~g}$ cetyl trimethyl ammonium bromide (CTAB) in $300 \mathrm{~mL}$ water and add $2.1 \mathrm{~mL} 2 \mathrm{M} \mathrm{NaOH}$, stirring magnetically and heating to $70{ }^{\circ} \mathrm{C}$, add $3 \mathrm{~mL}$ TEOS, $18 \mathrm{~mL}$ ethyl acetate and $1.8 \mathrm{~mL}$ APS to the mixture and stir at $70^{\circ} \mathrm{C}$ for $3 \mathrm{~h}$. After centrifugation, wash with ethanol for 3 times, and then disperse into ethanol. Add $50 \mathrm{mg} \mathrm{NH} \mathrm{NO}_{3}$ and stir for $3 \mathrm{~h}$ at 60 ${ }^{\circ} \mathrm{C}$. Wash with ethanol for 2 times. Dry at $60{ }^{\circ} \mathrm{C}$ overnight. MSN-20 was obtained by incubation in $\mathrm{Na}_{2} \mathrm{CO}_{3}$ solution (pH 12) at $50{ }^{\circ} \mathrm{C}$. For the synthesis of Gd@C-dots, MSN-20 were first incubated in a solution containing $100 \mathrm{mM} \mathrm{Gd}\left(\mathrm{NO}_{3}\right)_{3}$ and $10 \mathrm{mM}$ Gd-DTPA. Then, the Gd-loaded MSNs were left to dry on a crucible and were calcined at $300^{\circ} \mathrm{C}$ for $2 \mathrm{~h}$ in air. The raw products were dispersed in water and purified with centrifugal filter units ( $\mathrm{MWCO}=100-3 \mathrm{~K}$ removed aggregations of nanoparticles and unreacted precursors, respectively). The yielded Gd@C-dots were spherical, with an average diameter of $\sim 20$ $\mathrm{nm}$ and relatively narrow size distribution. The affibody ana-

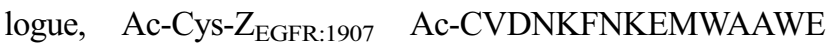
EIRNLPNLNGWQMTAFIASL

VDDPSQSANLLAEAKKLNDAQAPK-NH2, was prepared by solid-phase peptide synthesis as previously described. $^{21-23}$ The peptide was purified by RP-HPLC on a C-4 column and the purity of the product was confirmed by analytical HPLC. ${ }^{21,24}$ There was a notable amination 

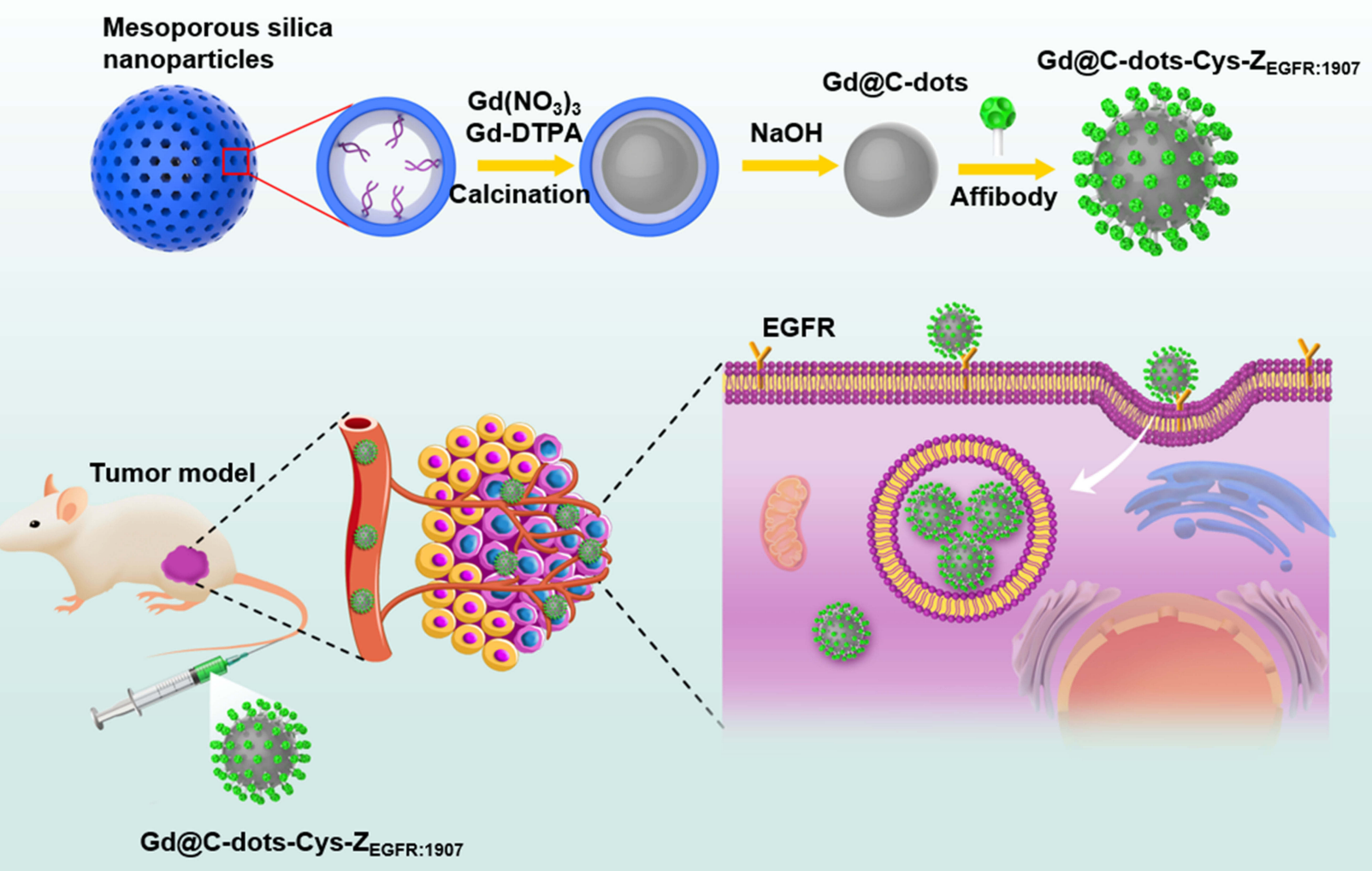

Figure I Schematic of preparation for Gd@C-dots-Cys-Z $Z_{\text {EGFR:1907 }}$ and its mechanism targeting to EGFR.

condensation reaction in Gd@C-dots and Ac-Cys-Z Gd@C-dots were dispersed in borate buffer, and carbodiimide (EDC) and N-hydroxysuccinimide (NHS) (10X) were added $(\mathrm{pH}=5.5)$. The mixture was magnetically stirred for $30 \mathrm{~min}$ and centrifuged with centrifugal filter units $(\mathrm{MWCO}=3 \mathrm{~K})$. Then the reaction products were dispersed in borate buffer and

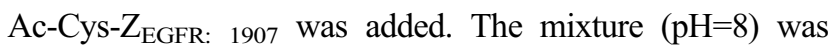
incubated for $2 \mathrm{~h}$ with gentle agitation and the product was collected with a centrifugal filtration unit (Millipore filter unit: MWCO 10K) and re-dispersed in PBS ( $\mathrm{pH}=7.4)$.

\section{Characterization of Gd@C-Dots- Cys-Z EGFR: 1907}

The size, morphology, and optical properties of the Gd@C-dots and Gd@C-dots-Cys-Z $Z_{\text {EGFR:1907 were charac- }}$ terized by dynamic light scattering (DLS), transmission electron microscopy (TEM), SpectraMax M2. The result of DLS measurement is presented at number-based distribution. Absorption and photoluminescence spectra were used to confirm the attachment of affibody onto the surface of Gd@C-dots. We assessed the T1 relaxivity of Gd@C-dots-

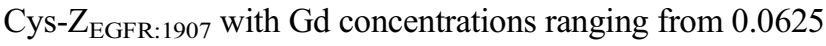

to $0.5 \mathrm{mM}$ and suspended in $1 \%$ agarose gel in $500 \mu \mathrm{L}$ PCR tubes. T1 weighted MR images of the samples were acquired on a 3.0T MR system with a four-channel small animal coil. The parameters used were as follows: T1WI:TR/TE $=600$ / $9.4 \mathrm{~ms} ; 128 \times 128$ matrices; and repetition times $=4$. To measure the longitudinal relaxation time of each sample, multiTR FSE sequence with TE (11.8ms), multi-TR (60, 100, 200, $500,800,1000,1200,1500,2000,2500 \mathrm{~ms}$, respectively) was performed.

\section{Cell Culture and Tumor Xenograft Model}

HCC827 human lung adenocarcinoma cell line (EGFR expression-positive cell line) and NCI-H520 human squamous cell carcinoma cell line (EGFR expression negative cell line) were purchased from ATCC. They were cultured routinely in RPMI 1640 (Hyclone USA) supplemented with 10\% fetal calf serum (Hyclone USA) under $5 \% \mathrm{CO}_{2}$, at $37{ }^{\circ} \mathrm{C}$. All cultures were passaged 3-4 times per week to maintain logarithmic growth. All the animal experiments performed in this study were approved by the Harbin Medical University animal ethics committee (Harbin Medical University Harbin, China) and the study was carried out in strict accordance with the 
recommendations in the Guide for the Care and Use of Laboratory Animals of the National Institutes of Health. Athymic nude mice (female, 4-6 weeks) were purchased from Beijing Vital River Laboratory Animal Technology Company. Mice were fed in an SPF room. The tumor model was established by subcutaneous injection of $5 \times 10^{6} \mathrm{HCC} 827$ or NCI-H520 cells into the right lower flank of athymic nude mice. When the tumor volumes reached $300-500 \mathrm{~mm}^{3}$, MR scans were performed.

\section{Western Blots}

To assess EGFR expression, total protein samples were extracted from HCC827 and NCI-H520 cells in lysis buffer (RIPA) containing protease inhibitor (PMSF). The resulting lysates were centrifuged at $13.2 \times 10^{3} \mathrm{rpm}$ for $15 \mathrm{~min}$ and the supernatants were collected. The protein concentrations were measured using the BCA protein assay kit (Solebo biotech Ltd). SDS-PAGE and Western blotting were performed using $80 \mu \mathrm{g}$ of proteins. The lysates were resolved by electrophoresis ( $70 \mathrm{~V}$ for $25 \mathrm{~min}$ and $110 \mathrm{~V}$ for $1.5 \mathrm{~h}$ ) and transferred onto NC membranes. After blocking in 5\% nonfat milk for $2 \mathrm{~h}$, the blots were incubated with the first antibody: rabbit anti-human EGFR monoclonal (1:1000, Abcam) and mouse anti-human GAPDH (1:1500, Abcam) were used as a loading control overnight at $4{ }^{\circ} \mathrm{C}$. The blots were washed and incubated with the second antibody: goat anti-rabbit IgG HRP-linked antibody (1:5000, Cell Signaling Technology); goat anti-mouse antibody (1:5000, Cell Signaling Technology) at room temperature for $1.5 \mathrm{~h}$. Western blot bands were captured by the ECL Western blotting detection system (BD). GAPDH was used as a loading control. After development, the films were scanned with BIO-RAD Gel Doc XRS ${ }^{+}$. The images were opened and analyzed by ImageLab (BIO-RAD) software. Three samples of each tumor cell type were prepared for Western blot to obtain semi-quantitative data for statistical analyses.

\section{Immunofluorescence}

HCC827 and NCI-H520 cells were cultured on a sterile glass at $37{ }^{\circ} \mathrm{C}$ with $5 \% \mathrm{CO}_{2}$. After washing with PBS, the cells were fixed with $4 \%$ paraformaldehyde (PFA) for 10 minutes. The mice were sacrificed after MRI scanning for harvesting the tumor tissues for immunofluorescence. Frozen tumor tissue slices $(5 \mu \mathrm{m})$ of HCC827 and NCIH520 were fixed with 4\% paraformaldehyde (PFA) for 10 minutes. After blocking with 5\% goat serum incubated for $1 \mathrm{~h}$, the cells and tumor tissue slices were incubated with primary antibody rabbit anti-human EGFR monoclonal (1:50, Abcam) overnight at $4{ }^{\circ} \mathrm{C}$, washed and incubated with secondary antibody goat anti-rabbit (1:250, Invitrogen). The samples were observed with a confocal microscope (Nikon).

\section{In vitro Cell Uptake Studies}

HCC827 and NCI-H520 cells were cultured on a sterile glass in petri dishes and then incubated in $1 \mathrm{~mL}$ of media containing Gd@C-dots-Cys-Z $Z_{\text {EGFR:1907 }}(50 \mu \mathrm{g} \mathrm{Gd} / \mathrm{mL})$ for $1 \mathrm{~h}$ at 37 ${ }^{\circ} \mathrm{C}$. After incubation, the cells were washed with PBS three times and then fixed with 4\% PFA. Similarly, $10^{6}$ of HCC827 and NCI-H520 cells in 6-well plates were incubated with Gd@C-dots-Cys-Z $Z_{\text {EGFR:1907 }}(50 \mu \mathrm{g} \mathrm{Gd} / \mathrm{mL})$ for $1 \mathrm{~h}$ at $37{ }^{\circ} \mathrm{C}$, $5 \% \mathrm{CO}_{2}$. For the blocking experiment, HCC827 cells were pretreated with $500 \mu \mathrm{M}$ Ac-Cys- $Z_{\mathrm{EGFR}: 1907}$ for $45 \mathrm{~min}$ before the addition of Gd@C-dots-Cys- $Z_{\text {EGFR:1907. After washing }}$ with PBS three times, the cells were detached by tyrosine treatment and harvested by centrifugation. They were counted with a hemocytometer and then suspended in $1 \%$ agarose in 500ul PCR tubes for MR imaging. T1WI MR images were acquired with the following parameters: TR/TE =600/9.4ms; matrix: 128×128; and NEX: 4. HCC827 cells after uptake also observed by transmission electron microscopy (TEM).

\section{In vivo MR Imaging of Subcutaneous Tumor Xenografts}

HCC827 and NCI-H520 tumor xenograft models were intravenously injected with Gd@C-dots-Cys-Z $Z_{\text {EGFR:1907 }}$ (3.2 mg Gd/kg). Gd@C-dots and Gd-DTPA-BMA (3.2 mg $\mathrm{Gd} / \mathrm{kg}$ ) were also injected into HCC827 tumor xenograft models. T1-weighted images were acquired before injection, and $10 \mathrm{~min}, 30 \mathrm{~min}, 1 \mathrm{~h}, 2 \mathrm{~h}$, and $4 \mathrm{~h}$ after injection with the following parameters: T1-weighted: Fast Spin Echo, FOV: $8 \mathrm{~cm} \times 4.8 \mathrm{~cm}$; thickness $2.0 \mathrm{~mm}$; TR: 600ms; TE: $9.8 \mathrm{~ms}$; flip angle: $142^{\circ}$; matrix: $128 \times 128$; NEX: 4. Signal-to-background ratio (SBR) was calculated by finely analyzing regions of interest (ROIs) of the MR images and $\mathrm{SBR} / \mathrm{SBR}_{0}$ was calculated to represent the signal changes. Signal intensity (SI) of tumor, liver, kidney and muscle were measured before and after the injection of the contrast agents. The mean SI measurements of three mice per group were used for statistical analysis. For each mouse, 3-5 ROIs were selected to measure SI of tumors, liver, kidney and muscle. The SBR values were calculated according to $\mathrm{SBR}=\mathrm{SI}$ organ/SI muscle. 


\section{Ex vivo Biodistribution of Gd@C-Dots- Cys-Z EGFR:1907}

To assess the biodistribution of Gd@C-dots-Cys-Z the mice were sacrificed $4 \mathrm{~h}$ after injection and the organs and tumors were collected for fluorescence and ICP-MS analyses. In ICP-MS experiments, tissue was dispersed in $5 \mathrm{~mL}$ of aqua regia $\left(67 \% \mathrm{HNO}_{3} / 37 \%\right.$ hydrochloric acid $\left.(\mathrm{w} / \mathrm{w})\right)$ for $4 \mathrm{~h}$ at 80 ${ }^{\circ} \mathrm{C}$ and, subsequently, the samples were diluted with $\mathrm{HNO}_{3}$ $2 \%(\mathrm{w} / \mathrm{w})$ matrix to adjust the volume to $5 \mathrm{~mL}$, filtered $(0.22$ $\mu \mathrm{m})$ and analyzed by ICP-MS. For calibration of the inductively coupled plasma mass spectrometry (ICP-MS), singleelement standard solutions were prepared by successive dilution in a $\mathrm{HNO}_{3} 2 \%(\mathrm{w} / \mathrm{w})$ matrix from a $1000-\mathrm{ppm} \mathrm{Gd}$ standard acquired from SCP Science. Based on the fluorescence characteristics of Gd@C-dots, the liver, spleen, and kidney were collected before injection and $4 \mathrm{~h}$ after injection. Slices of $5 \mu \mathrm{m}$ thickness were prepared and nuclei were stained with propidium iodide (PI). The distribution of Gd@C-dots-Cys- $Z_{\text {EGFR:1907 in major organs was analyzed }}$ with a confocal fluorescence microscope.

\section{Toxicity of Gd@C-Cys-Z}

In vivo toxicity of Gd@C-dots-Cys- $Z_{\mathrm{EGFR}: 1907}$ was determined in mice (18-25 g, n=3). Typically, Gd@C-dotsCys- $Z_{\text {EGFR:1907 }}(3.2 \mathrm{mg} \mathrm{Gd} / \mathrm{kg})$ were injected into the tail vein. As control group, an equal volume of saline solution was injected into the tail vein $(18-25 \mathrm{~g}, \mathrm{n}=3)$. The kidney, liver, spleen, and lung were harvested at $4 \mathrm{~h}$ after injection. Hematoxylin and eosin (H\&E) staining were performed to investigate any morphology changes after injection with Gd@C-dots-Cys-Z Z

\section{Statistical Analysis}

Statistics were performed using the data analysis package within GraphPad Prism 6.0 for Windows (GraphPad Software, San Diego, CA). Unless otherwise stated, tests compare two means with two-tail unpaired Student's $t$-tests, with equal variance assumed. Error bars indicate standard error of the mean (SEM) unless otherwise stated. All data are expressed as mean \pm standard deviation (SD). The in vivo targeting ability of Gd@C-dots-Cys-Z $Z_{\mathrm{EGFR}: 1907}$ at different time points, and with different contrast agents, were analyzed by one-way ANOVA. Comparisons of biodistribution of Gd@C-dots-Cys-Z $Z_{\mathrm{EGFR}: 1907}$ in liver, spleen, kidney, lung, and tumor were analyzed by two-way ANOVA. $P<0.05$ was considered statistically significant. All MR images were analyzed by ImageJ software.

\section{Results}

\section{Characterization of Gd@C-Dots-}

\section{Cys-Z EGFR:1907}

We prepared Gd@C-dots-Cys- $Z_{\mathrm{EGFR}: 1907}$ by conjugation of the affibody Ac-Cys- $Z_{\mathrm{EGFR}: 1907}$ coupled to the carboxyl group onto the surface of Gd@C-dots nanoparticles. High-resolution TEM imaging of the nanoparticles (Figure 2A and B) showed that it had regular shape and relatively uniform size. DLS revealed that the hydrodynamic diameters of Gd@C-dots and Gd@C-dots-Cys-Z $Z_{\text {EGFR:1907 were 21.5 } 2.2}$ $\mathrm{nm}$ (Figure 2C) and 25.1 $\pm 3.0 \mathrm{~nm}$ (Figure 2D), respectively. Gd@C-dots showed a broad absorption band between $200 \mathrm{~nm}$ and $500 \mathrm{~nm}$, with a shoulder appearing at $280 \mathrm{~nm}$ which had changed after the attachment of affibody. A red shift emerged in the photoluminescence spectrum of Gd@C-dots-

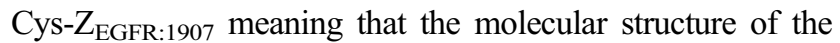
probe changed. Gd@C-dots and Gd@C-dots-Cys- $Z_{\mathrm{EGFR}: 1907}$ were also highly fluorescent, and both can be excited by light of a wide range of wavelengths to emit photoluminescence (Figure 2E and F). Figure 2G showed a representative T1WI image of different Gd concentrations of Gd@C-dotsCys- $Z_{\text {EGFR:1907. }} \mathrm{T} 1$ relaxivity analyzed with $3.0 \mathrm{~T}$ MR on agarose samples of Gd@C-dots-Cys- $Z_{\text {EGFR:1907 revealed }}$ a relativity $\mathrm{r} 1$ of $2.55 \mathrm{~s} \mathrm{~s}^{-1} \mathrm{mM}^{-1}$ (Figure $2 \mathrm{H}$ ). This enhanced r1 was mainly attributed to the increase in the rotational correlation time $(\tau R)$ as a result of binding $\mathrm{Gd}$ to a nanoparticle.

\section{EGFR Expression in $\mathrm{HCC} 827$ and $\mathrm{NCl}-\mathrm{H} 520$ Cells}

To measure total EGFR expression levels in HCC827 and NCI-H520 cells, we performed Western blots and immunofluorescence analyses. Total EGFR in HCC827 cells detected by Western blots was significantly higher than in NCI-H520 cells (Figure $3 \mathrm{~A}$ and $\mathrm{B}, P<0.05$ ). The results were consistent with the immunofluorescence analysis (Figure 3C and D), which also showed that total EGFR expression in HCC827 cells was higher than in NCI-H520 cells.

\section{EGFR Expression in $\mathrm{HCC} 827$ and $\mathrm{NCl}-\mathrm{H} 520$ Tumor Tissue}

Based on the results above, HCC 827 and NCI-H520 xenografts models were generated to present lung tumors with high- and no-EGFR expression, respectively, for subsequent imaging studies. Subcutaneous tumor tissues $(n=3$ 
A

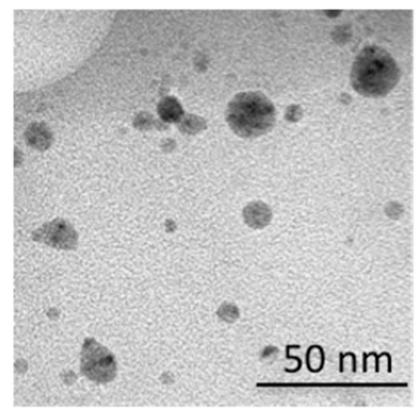

B

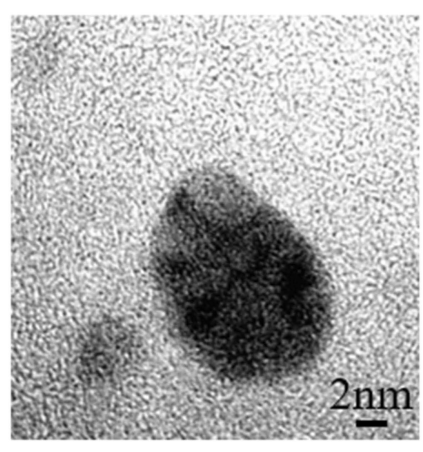

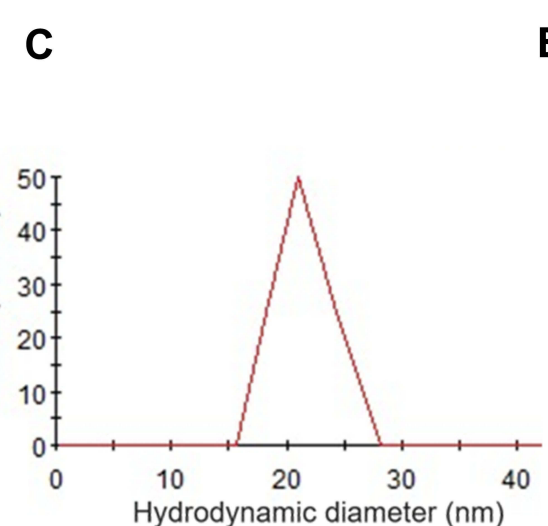

D

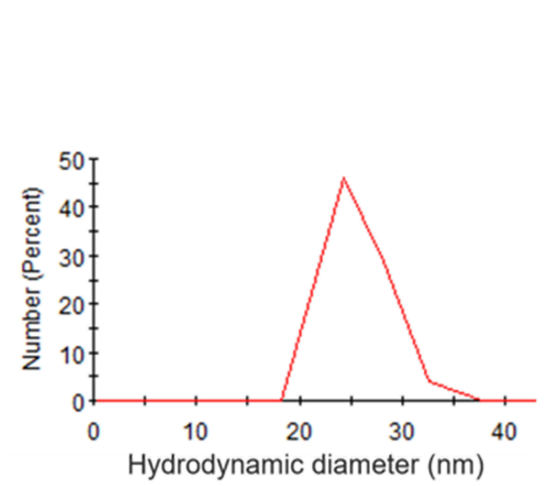

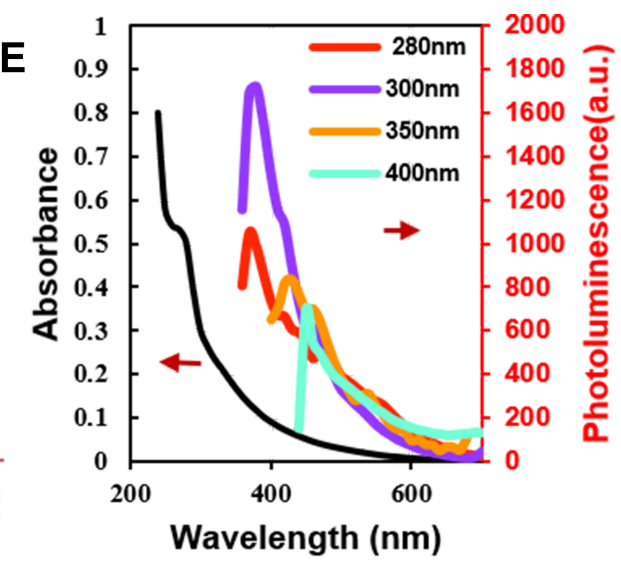

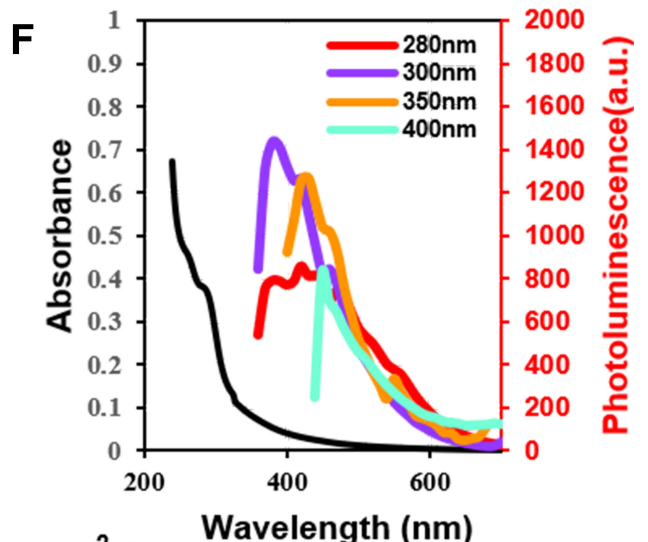

G

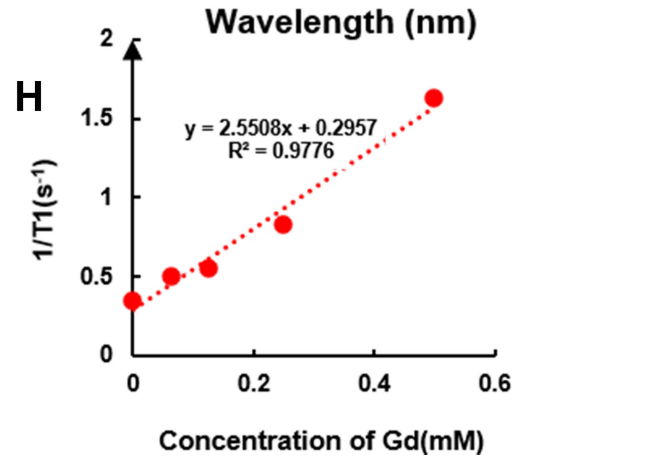

Figure 2 Characterization of Gd@C-dots and Gd@C-dots-Cys-Z EGFR:1907. (A) and (B) TEM images of Gd@C-dots; (C) DLS analysis results of Gd@C-dots; (D) DLS analysis results of Gd@C-dots-Cys-Z Representative TIWI MR images of Gd@C-dots-Cys-Z concentration. The slope of the regression line corresponds to the longitudinal relaxivity $(\mathrm{rl})$, the $\mathrm{rl}$ of Gd@C-dots-Cys- $\mathrm{Z}_{\mathrm{EGFR}: 1907}$ is $2.55 \mathrm{~s}^{-1} \mathrm{mM}^{-1}$.

for each tumor model) were harvested for assessment of EGFR expression by immunofluorescence which indicated HCC827 tumor tissue showed high EGFR expression, whereas NCI-H520 xenografts had no detectable EGFR expression (Figure $3 \mathrm{E}$ and $\mathrm{F}$ ).

\section{In vitro Gd@C-Dots-Cys-Z EGFR:1907 Cell Uptake}

Gd@C-dots-Cys-Z $Z_{\text {EGFR:1907 was incubated with HCC827 and }}$ NCI-H520 respectively. After $1 \mathrm{~h}$ of incubation, we could detect a significantly higher fluorescence signal (ex/em: 360/ $460 \mathrm{~nm}$ ) in HCC827 cells when compared to NCI-H520 cells (Figure 4A and B), that was in agreement with our T1-weighted MRI results. Moreover, when compared to the negative control, the T1-weighted MR signal in HCC827 cells was notably enhanced $(61.8 \%)$, whereas the signal in NCIH520 cells only increased slightly (19.8\%) (Figure 4C). These results show that EGFR-positive cells have a high uptake of Gd@C-dots-Cys-Z $\mathrm{EGFR}_{\text {:1907. }}$ Also, cellular uptake in HCC827 cells was dramatically decreased upon pretreatment of the Gd@C-dots with Ac-Cys-Z $Z_{\text {EGFR:1907 }}$ (Figure 4D), indicating 


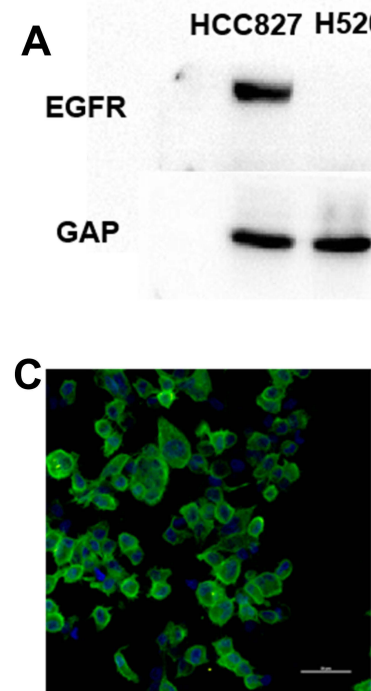

HCC827

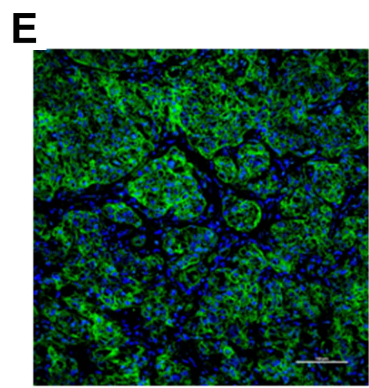

HCC827
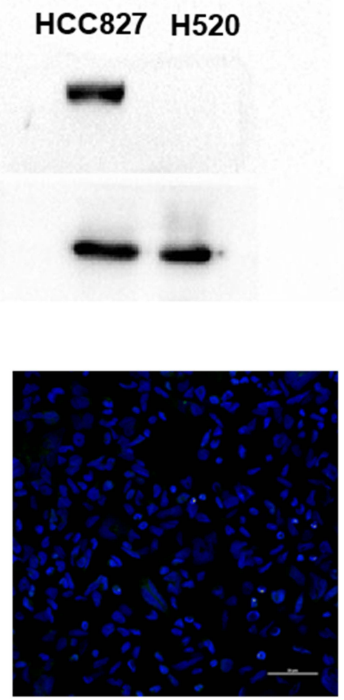

H520

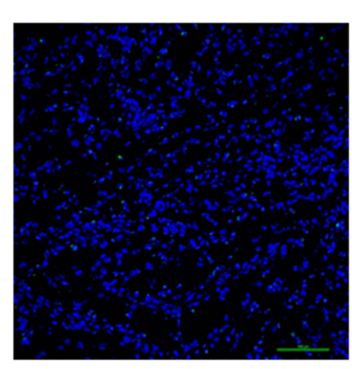

H520
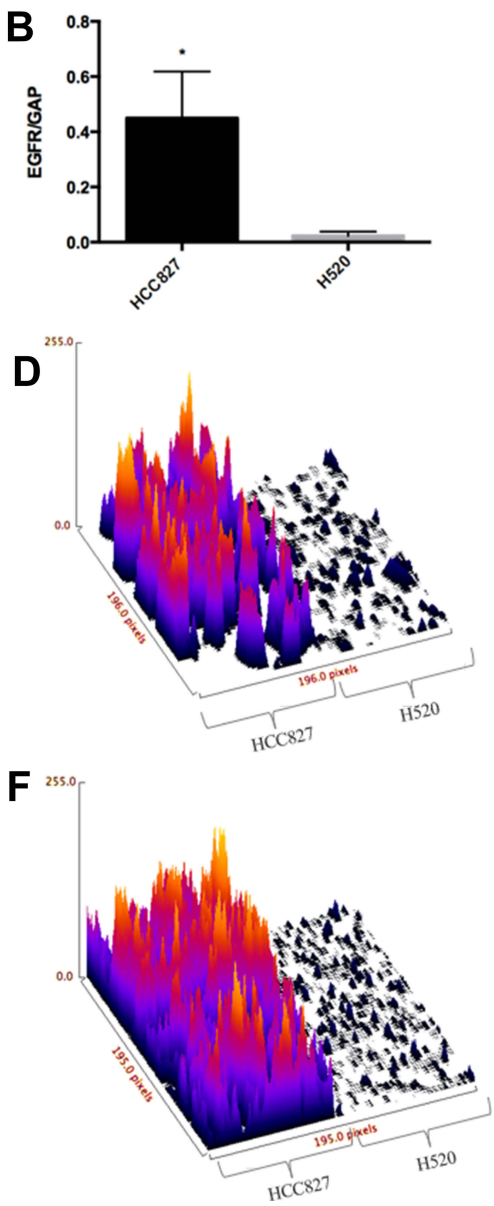

Figure 3 EGFR expression analysis. (A) Western blot analysis of EGFR expression. (B) Quantitative analysis of Western blot results for EGFR expression, (*P<0.05). (C and D) Immunofluorescence staining and surface plot of EGFR in HCC827 and H520 cells (200X), scale bar-50 $\mu$ m. (E and F) Immunofluorescence staining and surface plot of EGFR in HCC827 and H520 tumor tissues (200X), scale bar- $100 \mu \mathrm{m}$.

that it was mostly mediated by specific binding of the nanoparticles to EGFR. These differences in cellular uptake can also be discerned by MRI. TEM revealed that most of nanoprobes were targeted to the plasma membrane and a smaller proportion was transported into the cytoplasm by endocytosis (Figure 4E and F). Together these results demonstrate that

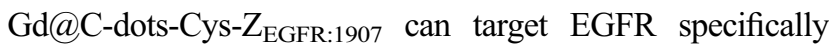
in vitro.

\section{Gd@C-Dots-Cys-Z $Z_{\text {EGFR:1907 Imaging in }}$ Subcutaneous Tumor Xenografts}

To assess the EGFR-targeting specificity of Gd@C-dots-

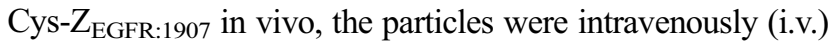
injected $(3.2 \mathrm{mg} \mathrm{Gd} / \mathrm{kg}$ ) into HCC827 and NCI-H520 tumor xenografts nude mice models $(n=3)$. T1-weighted images were acquired before and $10 \mathrm{~min}, 30 \mathrm{~min}, 1 \mathrm{~h}, 2 \mathrm{~h}$, and 4 $\mathrm{h}$ after injection. The T1WI tumor signal was significantly enhanced in EGFR-positive HCC827 models, when compared to NCI-H520 tumor models (Figure 5A and B). We detected an initial increase in the signal throughout the body. At 1 $\mathrm{h}$ after injection, the signal started decaying and after $4 \mathrm{~h}$, it had subsided to pre-injection levels. In HCC827 tumor models, $\mathrm{SBR} / \mathrm{SBR}_{0}$ at $1 \mathrm{~h}$ after injection $(137.4 \pm 4.6 \%)$ was higher than that before and $2 \mathrm{~h}(109.95 \pm 9.5 \%)$ or $4 \mathrm{~h}(112.5 \pm 4.3 \%)$ after injection (Figure 5C, $P<0.05$ ). Moreover, the signal enhancement in HCC827 tumors $(137.4 \pm 4.6 \%)$ was higher than that in NCI-H520 tumors $(105.3 \pm 2.5 \%)$ at $1 \mathrm{~h}$ after injection (Figure 5D, $P<0.001$ ). Finally, the signal enhancement of the non-targeting contrast agents Gd@C-dots and GdDTPA-BMA were significantly lower than the Gd@C-dots-

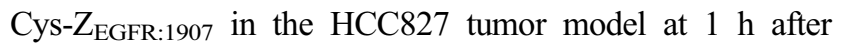
injection (Figure S1, $P<0.0001$ ). Although Gd-DTPA-BMA had strong signal enhancement after injection, there was no tumor-specific. 
A

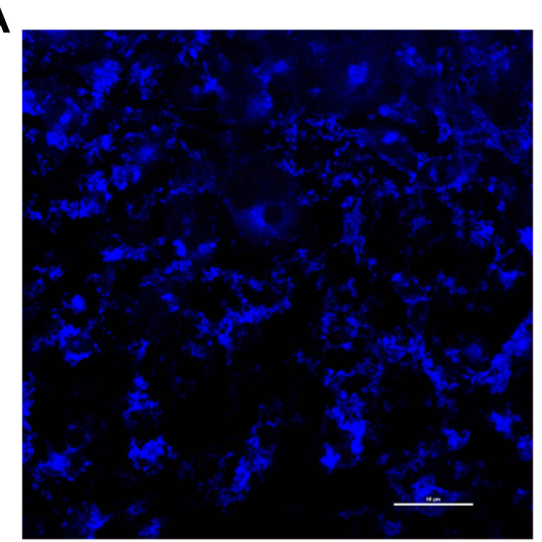

C

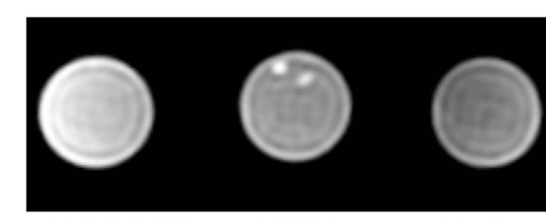

E

HCC827

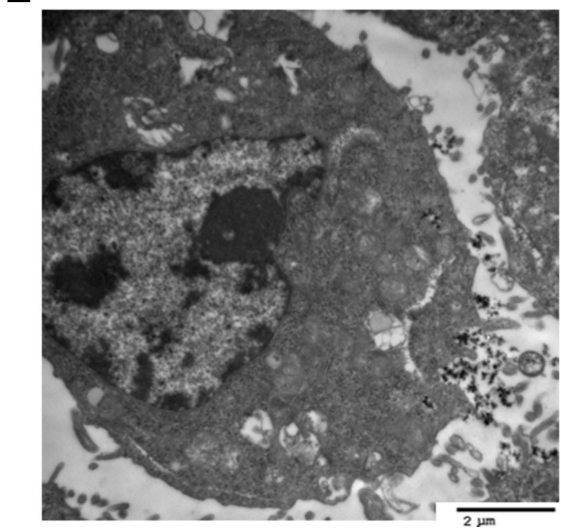

B

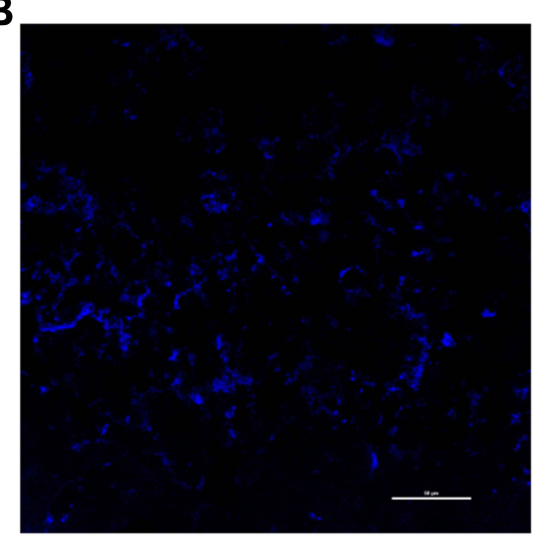

H520

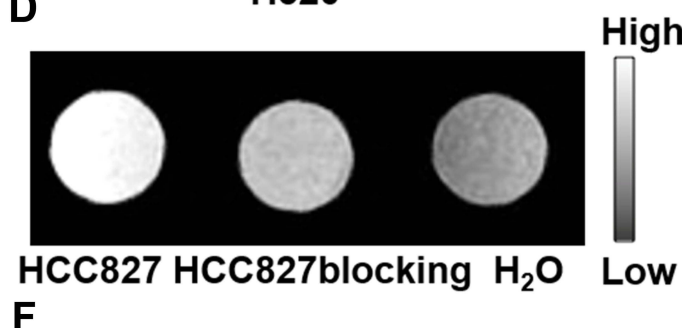

$\mathbf{F}$

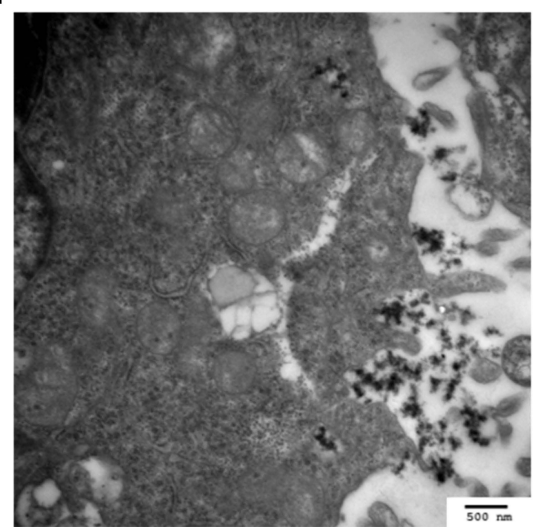

Figure 4 Cell uptake assay of Gd@C-dots-Cys-Z

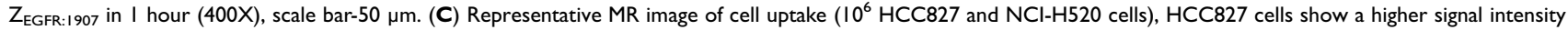
(61.8\%) than NCl-H520 (19.8\%) and negative control. (D) Representative MR image of cell uptake-blocking, HCC827 cells show a higher signal intensity. (E and F) TEM

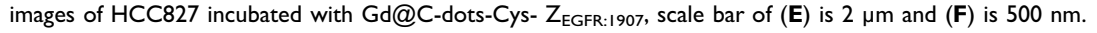

\section{Biodistribution of Gd@C-Dots- Cys-Z EGFR:1907}

Biodistribution experiments showed that Gd@C-dotsCys- $Z_{\text {EGFR:1907 }}$ signal intensity increased in the kidney but started decaying after $1 \mathrm{~h}$, and reached pre-injection levels after $2 \mathrm{~h}$. The signal in the liver increased and remained stable throughout the experiment (Figure 5E). Following a significant increase of the signal in the bladder from $10 \mathrm{~min}$ to $2 \mathrm{~h}$ after injection, it decreased to pre-injection levels at $4 \mathrm{~h}$ (Figure 6A). In contrast, there was no signal enhancement with Gd@C-dots (Figure 6B). These results demonstrated that Gd@C-dots modified with AcCys-Z $Z_{\text {EGFR:1907 }}$ owned effective renal clearance.

\section{Ex vivo Biodistribution of Gd@C-Dots- Cys-Z EGFR:1907}

Based on fluorescence properties of Gd@C-dots-

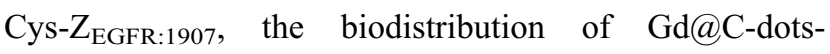

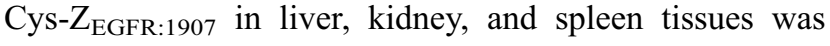
examined. No detectable probe fluorescence signal was observed in the kidney, whereas nanoparticle accumulation in the liver and spleen tissues were detected by fluorescence (Figure S2a). Moreover, Gd concentration measured by ICP-MS revealed that more than $60 \%$ of particles had been eliminated from the body after 4 hours. Most of the residual Gd@C-dots-Cys- $Z_{\mathrm{EGFR}: 1907}$ accumulated in the liver and spleen (Figure S2b, $\underline{\text { S2c) }}$. 
A Pre
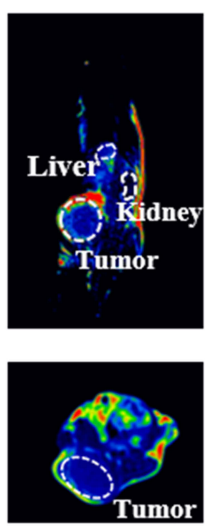

B Pre
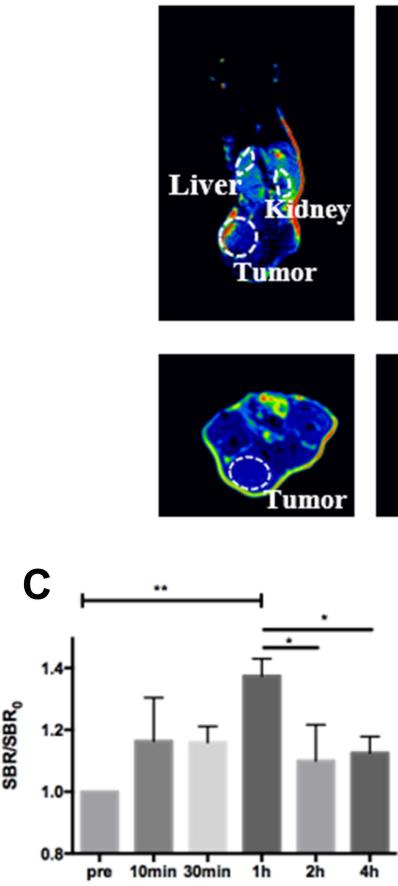

$10 \mathrm{~min}$
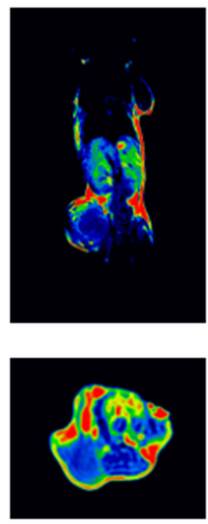

$10 \mathrm{~min}$
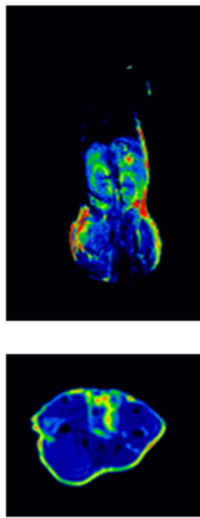

$30 \mathrm{~min}$
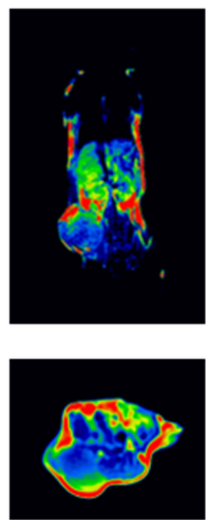

$30 \mathrm{~min}$
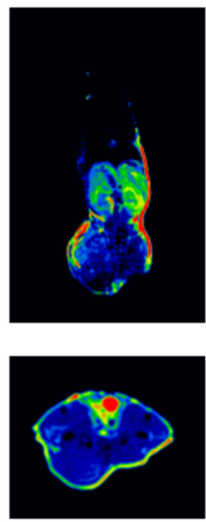

1h
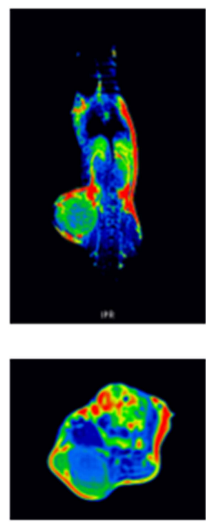

1h
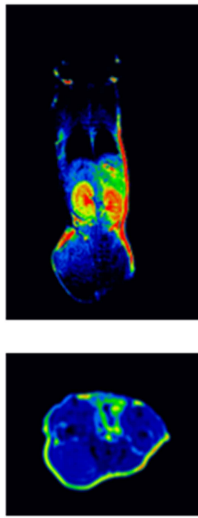

2h
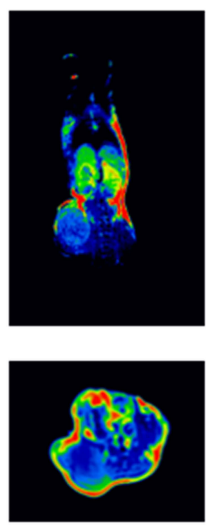

2h
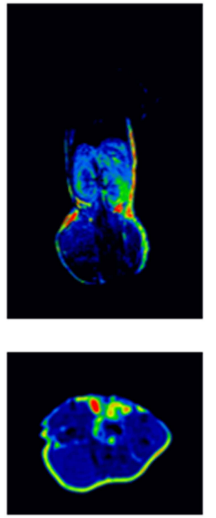

4h
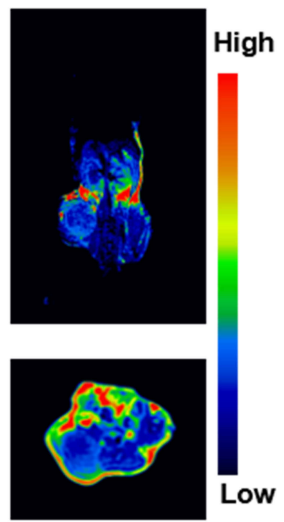

4h

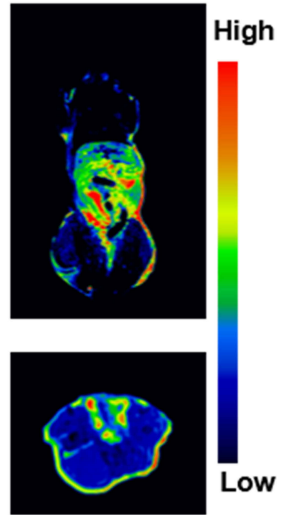

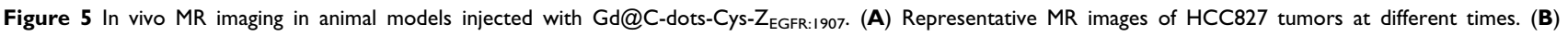
Representative MR images of $\mathrm{NCl}-\mathrm{H} 520$ tumors at different times. (C) Quantitative analysis of $\mathrm{MR}$ images in $\mathrm{HCC} 827, \mathrm{SBR}=\mathrm{SI}(\mathrm{tumor}) / \mathrm{SI}(\mathrm{muscle}),\left({ }^{*} \mathrm{P}<0.05, * * \mathrm{P}<0.0 \mathrm{I}\right)$. (D) Quantitative analysis of MR images between HCC827 and H520 tumor in I hour (****P<0.000I). (E) Quantitative analysis of MR images between liver and kidney signal intensity at different times. $\mathrm{SBR}=\mathrm{SI}$ (organ)/SI(muscle).

\section{Toxicity of Gd@C-Dots-Cys-Z EGFR:1907 in Mice}

Low biotoxicity is a crucial property of MRI contract probes used in clinical applications. To determine the bio-

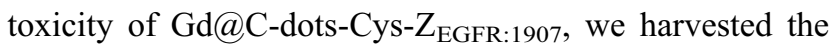
major organs of mice $4 \mathrm{~h}$ after injection of Gd@C-dotsCys- $Z_{\text {EGFR:1907 }}$ or saline solution. H\&E stainings on these tissues showed that the lung, liver, spleen, and kidney in mice injected with Gd@C-dots-Cys-Z $Z_{\text {EGFR:1907 had no }}$ morphological differences from those in mice injected with saline solution (Figure S3).

\section{Discussion}

Gd(III) chelates are the most commonly used MRI contrast agents in clinical settings. However, although these probes offer detailed anatomical images, Gd(III) chelates cannot provide molecular expression information and may cause toxicity, particularly in kidney failure patients. ${ }^{25}$ In this 
A

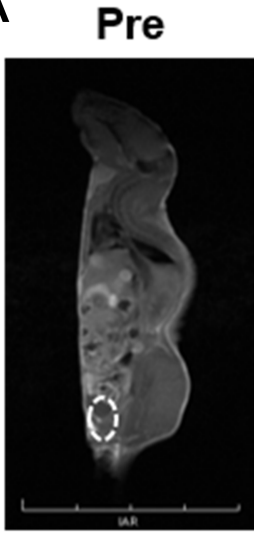

$10 \mathrm{~min}$

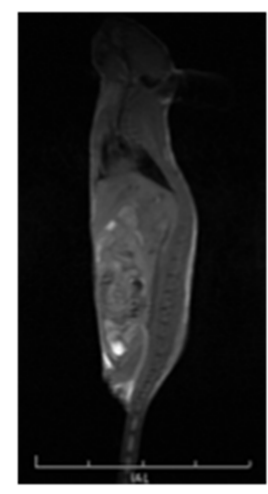

$30 \mathrm{~min}$

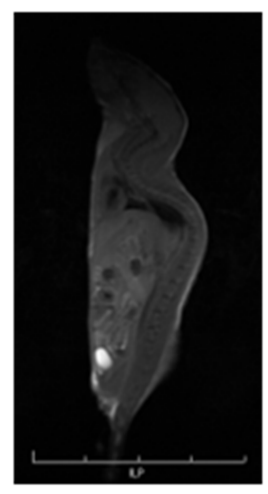

$1 \mathrm{~h}$

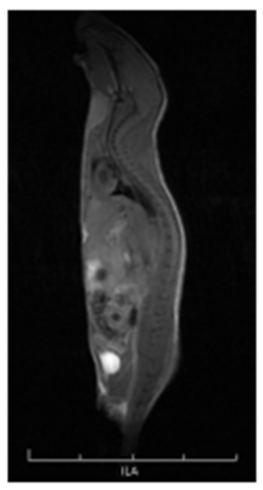

$2 \mathrm{~h}$

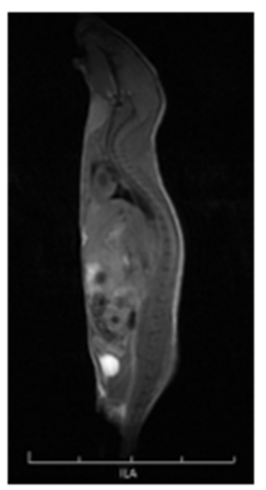

$2 \mathrm{~h}$

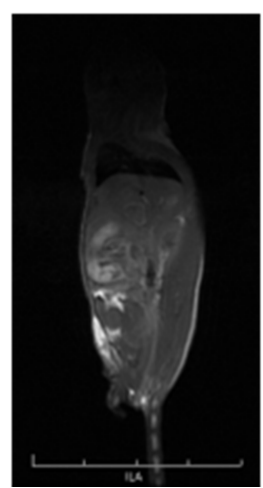

1h

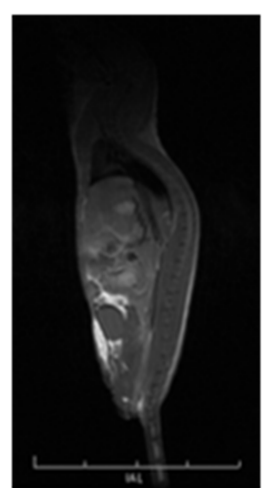

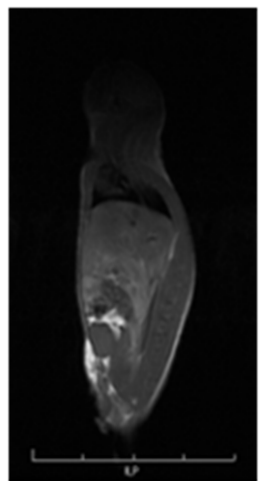

4h

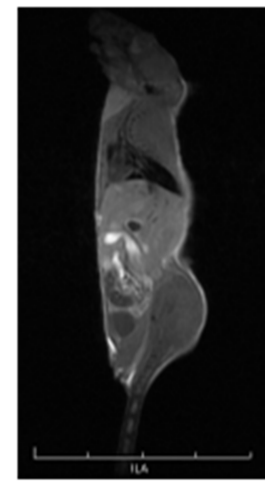

4h

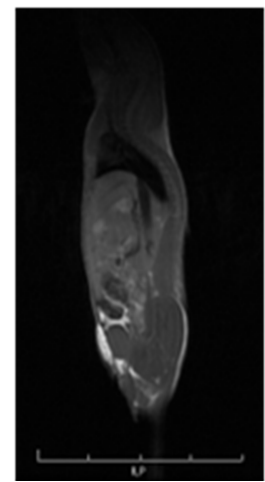

Figure 6 MR imaging of renal clearance. (A) Sagittal TI-weighted MR images of Gd@C-dots-Cys-Z EGFR:I907 in animal. (B) Sagittal TI-weighted MR images of Gd@C-dots in animal.

study, we developed EGFR-targeting Gd@C-dots that can be efficiently eliminated by the renal system. Moreover, this study shows that Gd@C-dots-Cys-Z $Z_{\text {EGFR:1907 does not }}$ cause biotoxicity in mice models. These results are consistent with our previous research claiming that the gadolinium in Gd@C-dots maintains an optimal T1 relaxivity without free $\mathrm{Gd}(\mathrm{III})$ release in the body. Moreover, a high concentration of Gd@C-dots results in low cellular toxicity when compared to Gd-DTPA. ${ }^{8}$ Other studies also indicate that carbon dots nanoparticles do not exert any significant toxic effect in vivo and in vitro. Biocompatibility, low cost, chemical inertness, and fluorescence are also recognized properties of carbon dots. ${ }^{26,27}$ Thus, Gd@C-dots modified with a targeting ligand may represent a potential safe molecular probe for clinical applications.

An ideal imaging probe can home efficiently to the diseased area after systemic injection, with the unbound being rapidly excreted from the host. However, because of their relatively large size, most nanoparticles tend to accumulate in major organs, such as liver, spleen, and lung. ${ }^{28-30}$ It is well established that nanoparticles measuring up to $5 \mathrm{~nm}$ can be cleared via the kidney, and our previous research showed that Gd@C-dots, which have diameters $\sim 12$ nm, can also be efficiently cleared by the renal system. ${ }^{8}$ In the current study, we demonstrate that Gd@C-dots-Cys- $Z_{\text {EGFR:1907 are efficiently }}$ excreted via urine, even though they measure $\sim 20 \mathrm{~nm}$, which exceeds the commonly assumed threshold for renal clearance. In contrast, Gd@C-dots on their own appear to be excreted less efficiently. Although the exact mechanism is unknown, the unique surface of Gd@C-dots-Cys-Z $Z_{\text {EGFR:1907 may likely }}$ facilitate clearance. Ac-Cys- $Z_{\mathrm{EGFR}: 1907}$ is quite hydrophilic and can be cleared via the kidney. ${ }^{17,21}$ On the other hand, Gd@C-dots have a shell of amorphous carbon decorated with carboxyl groups. Thus, Gd@C-dots-Cys- $Z_{\text {EGFR:1907 has }}$ a hydrophilic surface and a hydrophobic core, thereby affording the particles with good colloidal stability and the capacity to cross certain types of biological barriers. Indeed, it has previously been suggested that, in addition to particle size 
and shape, surface properties may facilitate renal clearance. $^{31,32}$ Mass balance of Gd@C-dots-Cys-Z $Z_{\text {EGFR:1907 }}$ can be revealed by in vivo imaging and ex-vivo biodistribution that significant increase of Gd-related signal in the bladder from 10 min to 2 h post injection indicating that Gd@C-dots-

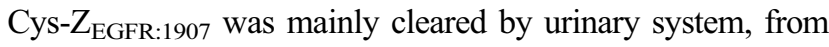
which 60\% of Gd@C-dots-Cys-Z $Z_{\text {EGFR:1907 }}$ can be excreted out at $4 \mathrm{~h}$ post injection as measured by ICP-MS in ex-vivo biodistribution study. In addition, like most nanoparticles, Gd@C-dots-Cys-Z Z EGFR:1907 can accumulate non-specifically in live and spleen as confirmed in both images and biodistribution results, for the reason of phagocytes in the reticuloendothelial. Future research should address these questions to improve the design of nanoparticles used for MRI.

Despite recent advances in the development of contrast agents and MR scanning technology, lung cancer diagnosis with MRI remains challenging, causes include limited spatial resolution, mismatched susceptibility between the air cavities and tissues in the lung, and respiratory and cardiac motion artifacts. Nevertheless, MRI provides excellent tissue differentiation, and high temporal and spatial resolution, which are fundamental for accurate cancer diagnosis. On the other hand, EGFR plays a curial role in NSCLC diagnosis and treatment. ${ }^{33}$ Thus, MRI with EGFR-targeting probes represents a promising approach for lung cancer diagnosis, and research efforts should be invested in developing safe and sensitive EGFR molecular targeting MR contrast agents. In this study, Gd@C-dots modified with Ac-Cys-Z $Z_{\text {EGFR:1907 }}$ shows highly specific EGFR-targeting ability in cell uptake assays and in vivo experiments with EGFR-expressing NSCLC subcutaneous xenograft mice models. Interestingly, we found that nanoparticle size affects the sensitivity of targeting. Indeed, 3 nm Gd@C-dots-Cys- $Z_{\text {EGFR:1907 }}$ shows lower signal enhancement in EGFR-expressing HCC827 xenografts (Figure S4a). This may be explained by poor binding to the targeted EGFR peptide, due to the reduced surface area of the nanoparticle. When compared with larger particles $(\sim 100 \mathrm{~nm})$, which allow many ligand-receptor interactions per particle, a small $(\sim 5 \mathrm{~nm})$ nanoparticle coated with $50-\mathrm{kDa}$ proteins may interact with only one or two cell receptors. Thus, a particle size that allows interactions with enough receptor peptide is necessary for targeted molecular imaging. ${ }^{34}$ Moreover, small particles are unsuitable for passive accumulation in the tumor compartment, due to a high rate of interstitial space permeation. ${ }^{35}$ Finally, small nanoparticles have short circulation time and rapid clearance from the kidney, which significantly reduces the probability of reaching and interacting with the surface of tumor cells. Indeed, after only 4 hours, the 3 nm Gd@C-dots-Cys-Z $Z_{\text {EGFR:1907 had been eliminated }}$ from the body (Figure S4b). Thus, our results suggest that a size of $\sim 20 \mathrm{~nm}$ optimizes the affinity and targeting ability of Gd@C-dots-Cys-Z $Z_{\text {EGFR:1907 to EGFR-expressing tumors }}$ in vivo, while allowing efficient renal clearance.

\section{Conclusion}

We have developed a new contrast agent for MRI,

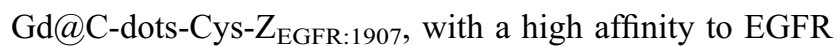
and efficient renal clearance. Gd@C-dots-Cys- $Z_{\mathrm{EGFR}: 1907}$ shows EGFR-specific binding in EGFR-expressing tumor cells in vitro and in vivo in NSCLC subcutaneous xenograft mice models. Moreover, Gd@C-dots-Cys- $Z_{\mathrm{EGFR}: 1907}$ are efficiently eliminated from the kidney, liver, and spleen, and without accumulation in the kidney. Finally, these nanoparticles do not cause biotoxicity. These results suggest that Gd@C-dots-Cys- $Z_{\mathrm{EGFR}: 1907}$ is a robust and highly specific MR contrast agent with clinical translation potential for the diagnosis of NSCLC.

\section{Abbreviations}

Gd@C-dots, Gd-encapsulated carbonaceous dots; NSCLC, non-small-cell lung cancer; NSF, nephrogenic systemic fibrosis; EGFR, epidermal growth factor receptor; DLS, dynamic light scattering; TEM, transmission electron microscopy; ICP-MS, inductively coupled plasma mass spectrometry.

\section{Statement}

The abstract of this paper was presented at the World Molecular Imaging Conference 2018 as a poster presentation with interim findings. The poster's abstract was published in "Poster Abstracts" in Molecular Imaging and Biology: Volume 20, Issue 1 Supplement, December $2018 \mathrm{https://}$ www.proxydgb.buap.mx:2067/journal/11307/20/1/suppl (Pages 585-787 ID27).

\section{Ethical Approval}

All animal experiments were approved by the Harbin Medical University Animal Ethics Committee in accordance with Chinese legislation and followed relevant guidelines. The institutional review board approved this study on mice with NSCLC tumor xenografts.

\section{Funding}

This work was supported by the National Natural Science Foundation of China (81627901, 81471724), the Tou-Yan Innovation Team Program of the Heilongjiang Province 
(2019-15), National Basic Research Program of China (2015CB931800), and the Key Laboratory of Molecular Imaging Foundation (College of Heilongjiang Province).

\section{Disclosure}

The authors have declared that no competing interest exists and that they have no conflicts of interest in this work.

\section{References}

1. Chang EH, Harford JB, Eaton MA, et al. Nanomedicine: past, present and future a global perspective. Biochem Biophys Res Commun. 2015;468(3):511-517. doi:10.1016/j.bbrc.2015.10.136

2. Le Duc G, Roux S, Paruta-Tuarez A, et al. Advantages of gadolinium based ultrasmall nanoparticles vs molecular gadolinium chelates for radiotherapy guided by MRI for glioma treatment. Cancer Nanotechnol. 2014;5(1):4. doi:10.1186/s12645-014-0004-8

3. Strijkers GJ, Mulder WJ, van Tilborg GA, Nicolay K. MRI contrast agents: current status and future perspectives. Anticancer Agents Med Chem. 2007;7(3):291-305. doi:10.2174/187152007780618135

4. Yang L, Krefting I, Gorovets A, et al. Nephrogenic systemic fibrosis and class labeling of gadolinium-based contrast agents by the Food and Drug Administration. Radiology. 2012;265(1):248-253. doi:10. 1148/radiol.12112783

5. Shen ZT, Zheng S, Gounis MJ, Sigalov AB. Diagnostic magnetic resonance imaging of atherosclerosis in apolipoprotein e knockout mouse model using macrophage-targeted gadolinium-containing synthetic lipopeptide nanoparticles. PLoS One. 2015;10(11):e0143453. doi:10.1371/journal.pone. 0143453

6. Plissonneau M, Pansieri J, Heinrich-Balard L, et al. Gd-nanoparticles functionalization with specific peptides for ss-amyloid plaques targeting. J Nanobiotechnol. 2016;14(1):60. doi:10.1186/s12951-016-0212-y

7. Cabrera-Garcia A, Vidal-Moya A, Bernabeu A, et al. Gd-Si Oxide nanoparticles as contrast agents in magnetic resonance imaging. Nanomaterials. 2016;6:6. doi:10.3390/nano6060109

8. Chen H, Wang GD, Tang W, et al. Gd-encapsulated carbonaceous dots with efficient renal clearance for magnetic resonance imaging. Adv Mater. 2014;26(39):6761-6766. doi:10.1002/adma.201402964

9. Bianchi A, Dufort S, Lux F, et al. Targeting and in vivo imaging of non-small-cell lung cancer using nebulized multimodal contrast agents. Proc Natl Acad Sci U S A. 2014;111(25):9247-9252. doi:10.1073/pnas.1402196111

10. Mendelsohn J, Baselga J. Status of epidermal growth factor receptor antagonists in the biology and treatment of cancer. J Clin Oncol. 2003;21(14):2787-2799. doi:10.1200/JCO.2003.01.504

11. Mitsudomi T, Yatabe Y. Epidermal growth factor receptor in relation to tumor development: EGFR gene and cancer. FEBS J. 2010;277 (2):301-308. doi:10.1111/j.1742-4658.2009.07448.x

12. Moroni M, Veronese S, Benvenuti S, et al. Gene copy number for epidermal growth factor receptor (EGFR) and clinical response to antiEGFR treatment in colorectal cancer: a cohort study. Lancet Oncol. 2005;6(5):279-286. doi:10.1016/S1470-2045(05)70102-9

13. Zhou W, Ercan D, Chen L, et al. Novel mutant-selective EGFR kinase inhibitors against EGFR T790M. Nature. 2009;462 (7276):1070-1074. doi:10.1038/nature08622

14. Nilsson FY, Tolmachev V. Affibody molecules: new protein domains for molecular imaging and targeted tumor therapy. Curr Opin Drug Discov Devel. 2007;10(2):167-175.

15. Tolmachev V, Orlova A, Nilsson FY, Feldwisch J, Wennborg A, Abrahmsen L. Affibody molecules: potential for in vivo imaging of molecular targets for cancer therapy. Expert Opin Biol Ther. 2007;7 (4):555-568. doi:10.1517/14712598.7.4.555
16. Qi S, Miao Z, Liu H, Xu Y, Feng Y, Cheng Z. Evaluation of four affibody-based near-infrared fluorescent probes for optical imaging of epidermal growth factor receptor positive tumors. Bioconjug Chem. 2012;23(6):1149-1156. doi:10.1021/bc200596a

17. Friedman M, Orlova A, Johansson E, et al. Directed evolution to low nanomolar affinity of a tumor-targeting epidermal growth factor receptor-binding affibody molecule. $J$ Mol Biol. 2008;376 (5):1388-1402. doi:10.1016/j.jmb.2007.12.060

18. Zhao P, Yang X, Qi S, et al. Molecular imaging of hepatocellular carcinoma xenografts with epidermal growth factor receptor targeted affibody probes. Biomed Res Int. 2013;2013:759057. doi:10.1155/ 2013/759057

19. Su X, Cheng K, Jeon J, et al. Comparison of two site-specifically (18) F-labeled affibodies for PET imaging of EGFR positive tumors. Mol Pharm. 2014;11(11):3947-3956. doi:10.1021/mp500 3043

20. Chen H, Wang GD, Sun X, et al. Mesoporous silica as nanoreactors to prepare Gd-encapsulated carbon dots of controllable sizes and magnetic properties. Adv Funct Mater. 2016;26(22):3973-3982. doi:10.1002/adfm.201504177

21. Miao Z, Ren G, Liu H, Jiang L, Cheng Z. Small-animal PET imaging of human epidermal growth factor receptor positive tumor with a $64 \mathrm{Cu}$ labeled affibody protein. Bioconjug Chem. 2010;21 (5):947-954. doi:10.1021/bc900515p

22. Gao J, Chen K, Miao Z, et al. Affibody-based nanoprobes for HER2-expressing cell and tumor imaging. Biomaterials. 2011;32 (8):2141-2148. doi:10.1016/j.biomaterials.2010.11.053

23. Hoppmann S, Miao Z, Liu S, et al. Radiolabeled affibody-albumin bioconjugates for HER2-positive cancer targeting. Bioconjug Chem. 2011;22(3):413-421. doi:10.1021/bc100432h

24. Troy T, Jekic-McMullen D, Sambucetti L, Rice B. Quantitative comparison of the sensitivity of detection of fluorescent and bioluminescent reporters in animal models. Mol Imaging. 2004;3(1):9-23. doi:10.1162/153535004773861688

25. Thomsen HS, Marckmann P, Logager VB. Nephrogenic systemic fibrosis (NSF): a late adverse reaction to some of the gadolinium based contrast agents. Cancer Imaging. 2007;7:130-137. doi:10.1102/1470-7330.2007.0019

26. Wang K, Gao Z, Gao G, et al. Systematic safety evaluation on photoluminescent carbon dots. Nanoscale Res Lett. 2013;8(1):122. doi:10.1186/1556-276X-8-122

27. Himaja AL, Karthik PS, Singh SP. Carbon dots: the newest member of the carbon nanomaterials family. Chem Rec. 2015;15(3):595-615. doi: $10.1002 /$ tcr. 201402090

28. Roggers R, Kanvinde S, Boonsith S, Oupicky D. The practicality of mesoporous silica nanoparticles as drug delivery devices and progress toward this goal. AAPS Pharm Sci Tech. 2014;15 (5):1163-1171. doi:10.1208/s12249-014-0142-7

29. Wang Q, Zhuang X, Mu J, et al. Delivery of therapeutic agents by nanoparticles made of grapefruit-derived lipids. Nat Commun. 2013;4:1867. doi:10.1038/ncomms2886

30. Li J, Pant A, Chin CF, et al. In vivo biodistribution of platinum-based drugs encapsulated into multi-walled carbon nanotubes. Nanomedicine. 2014;10(7):1465-1475. doi:10.1016/j.nano.2014.01.004

31. Liu J, Yu M, Zhou C, Zheng J. Renal clearable inorganic nanoparticles: a new frontier of bionanotechnology. Materials Today. 2013;16 (12):477-486. doi:10.1016/j.mattod.2013.11.003

32. Ehlerding EB, Chen F, Cai W. Biodegradable and renal clearable inorganic nanoparticles. $A d v \quad S c i$. 2016;3:2. doi:10.1002/ advs. 201600165

33. Chariou PL, Lee KL, Wen AM, Gulati NM, Stewart PL, Steinmetz NF. Detection and imaging of aggressive cancer cells using an epidermal growth factor receptor (EGFR)-targeted filamentous plant virus-based nanoparticle. Bioconjug Chem. 2015;26 (2):262-269. doi: $10.1021 / \mathrm{bc} 500545 \mathrm{z}$ 
34. Albanese A, Tang PS, Chan WC. The effect of nanoparticle size, shape, and surface chemistry on biological systems. Annu Rev Biomed Eng. 2012;14:1-16. doi:10.1146/annurev-bioeng-071811150124
35. Perrault SD, Walkey C, Jennings T, Fischer HC, Chan WC. Mediating tumor targeting efficiency of nanoparticles through design. Nano Lett. 2009;9(5):1909-1915. doi:10.1021/n1900031y

\section{Publish your work in this journal}

The International Journal of Nanomedicine is an international, peerreviewed journal focusing on the application of nanotechnology in diagnostics, therapeutics, and drug delivery systems throughout the biomedical field. This journal is indexed on PubMed Central, MedLine, CAS, SciSearch ${ }^{\circledR}$, Current Contents ${ }^{\circledR} /$ Clinical Medicine,
Journal Citation Reports/Science Edition, EMBase, Scopus and the Elsevier Bibliographic databases. The manuscript management system is completely online and includes a very quick and fair peer-review system, which is all easy to use. Visit http://www.dovepress.com/ testimonials.php to read real quotes from published authors. 